\title{
Identification and Ranking Indexes of Evaluation and Selection of Foresight Methods in Cultural Policy Making
}

\author{
Mohammad Mahdi Zolfagharzadeh ${ }^{1^{*}}$ \\ Saeed Khazaei2
}

Amirreza Naghsh ${ }^{3}$

Mahdi Fateh $\operatorname{Rad}^{4}$

\begin{abstract}
${ }^{*}$ Assistant Professor at Faculty of Management, University of Tehran, Tehran, Iran 2 Professor and Faculty Member of Imam Hossein University, Tehran, Iran ${ }^{3}$ Ph.D. Student in Futures Studies at Faculty of Management, University of Tehran, Tehran, Iran ${ }^{4}$ Assistant Professor and Faculty Member of Sharif University of Technology, Tehran, Iran ${ }^{*}$ Corresponding author: Mohammad Mahdi Zolfagharzadeh, E-mail: zolfaghar@ut.ac.ir
\end{abstract}

Doi:10.5901/mjss.2016.v7n1p80

\begin{abstract}
The present research has the purpose of identification and ranking indexes of evaluation and foresight methods selection in cultural policy making through survey methodology. Statistical population of this research includes 70 experts that 60 people were selected as sample volume by Cuchran's formula. The data collection instrument is the researcher's composed questionnaire the face, content, and structural validity was confirmed and its reliability was estimated 0.88 by alpha Cronbach coefficient. In order to analyze data, average and one-variable t-test, and factor loading analysis test are used through determination of KMO coefficient. The result of this research was seventh indexes identification and ranking of 32 from 42 identified indexes to evaluate and select foresight methods in cultural policy making. Among indexes such as method ability in making systematic attitude (holism), ability of identification political priorities, ability of method in cultural discoursing, capacity to make cultural participation, responsiveness to new evolutions, intuitive ability and exploratory of method, capacity to participate experts, extensiveness of various fields related to culture, accessibility of informational resources to use methods with the most factor loading. In addition, results obtained from ranking of indexes show that indexes such as capacity to participate experts, method ability for social networking, method ability in social networking, the security level of gathered data, reliance on expert power, implicit knowledge and people experience, method ability in imaging possible and probable futures in culture have the highest rank than other indexes in foresight methods selection in cultural policy making.
\end{abstract}

Keywords: politics, policy making, cultural policy making, foresight, culture, foresight methods

\section{Introduction}

The increasing references to national and transnational issues concerning "culture" have turned the significance of attention to strategic position of culture into a necessity. Political importance caused government not only use experiences and cultural and historical memory of other countries, but also identify probable cultural issues in futureoriented approach in policy making fields and be prepared in-advance to face with challenges. Therefore, future-oriented issues have been faced with daily-increasing sophistication in policy making field which is seen less in other foresight studies. To understand this sophistication, selecting foresight methods can be path finding with "culture" nature. Today, the connection between foresight and policy making has been concerned by many authorities of strategic science, but it seems that according to method references and existed technics in foresight, what can be understood by exploring foresight in policy making especially in culture field has been significant in selecting foresight methods which can have more validity than each cultural policy making steps against culture issue. Therefore, identification indexes enabling to be used in optimum foresight methods in cultural policy making is an issue we explore in this research. In this research after introducing methodology, findings and results are discussed. 


\section{Research Issue Definition}

Competitive advantage in cultural policy making is for government which try to predict future and make policies in this regard through beyond time studies. According to policy making point of view, cultural policy has strategic important and effectiveness on all stable development fields and is actually basis for all types of policy making for stable policy making. Infrastructures and landscapes should be considered simultaneously. This view to cultural policy making and its relationship with planning can lead us to rely on past cultural heritages and resources, talk about future, and be hopeful to make our future, because cultural policy making is not only policy making for today, but also a policy making to connect cultural heritage to future culture (Ashtarian, 2012)

In order to increase changes and consistent stability of new issues in global village, reliance on planning method to predict is not enough for macro management of states and dark shadow of uncertainty and consistency of unintegrated and strange events change situation so that future prediction in evolutionary world seems difficult. In this time, it is necessary to look to foresight state in policy making process which is always the main question of participators in foresight projects.

Foresight is an approach which tries to reinforce decision making process by improving inputs and making extensive social networks (which main difference is from future study or long-term planning). Today, foresight term is used extensively. This term shows vast spectrum of approaches improving decision making processes, approaches with long-term future thought, and focusing on strategic decision making processes and intelligent approximation in the same extent (Gavigan, 2001)

Future studies is not only limited to approximation of certain future events, but also includes favorite future determination and their methodology identification. Actually, foresight is pre-extension knowledge to make future and based on this belief that future is influenced by today actions and decisions. Actually, foresight emphasis is not on future prediction, but it is identification of proper actions to make future according to more precise actions for favorite future and minimizes uncertainty (Khazaee, 2008)

Lack of using foresight methods and technics, which is reason for development of developed countries in the world in policy made eras, in cultural policy making of some countries reduces effectiveness of this policy making and weakness in comprehensive, long-term, and futuristic attitude to draw cultural path in sophisticated and evolutionary conditions. This important challenge shows itself all over cultural policy making cycle which means initial policy making orientations (accurate discerning of problem and its identification), designing policies, and finally execution system and refining policies.

Orientation of the fourth generation of foresight on social and cultural issues on one hand, and increasing references of social issues to cultural issue on the other hand signifies cultural foresight more than ever (Jin, 2011) In Macro field of cultural policy making especially in last 2 decades, it has appreciated sufficiently for signifying issues such as cultural globalization, cultural engineering and joint, and cultural development. In this regard, foresight in cultural policy making field in macro level can change into an infrastructural issue.

One of the most important elements of foresight process is proper foresight method. To select foresight methods, there are various indexes which are expressed according to nature, issue, and region of foresight. Therefore, this question is asked whether various methods of foresight can be used for issues such as "cultural policy making" in spite of affluent advantages? So the most important issue in this research is identification and ranking selection of foresight methods for being new issue in cultural policy making. Therefore, we proposed these questions that: what are indexes of evaluation and selection of foresight methods in cultural policy making? How is their ranking?

\section{Theoretical Framework}

In present space, countries inter to such space that their actions and activities are inevitably influenced by cultural field evolutions. Although, parts of evolutions in culture field and other related evolutions are inevitable for countries and they are influenced of what happen in this field, significant part of these evolutions is predictable, understandable, and can be planned, controlled, and actually can be managed (Salehi Amiri, 2009). Uncertainty in social evolutions has changed knowledge of future to one of comparative advantage factors (Hergert, 2013). Future study is new born and modern knowledge, so it is now research topic (Stesfar) with wise literature body, status for discernable knowledge and definable limitations of conceptions, methodologies, activities and processes having more than 50 years background (Sardar, 2010). Therefore, it has mutual relationship with anthropology, sociology, and communities cultures so rooting about cultural planning and policy making becomes necessary (Malaska, 2008).

Foresight is a systematic, participative process gathering future conception that makes middle to long-term 
landscape by purpose of updating decisions and arranging mutual actions (Gayigan, 2001). This word was used at the end of 80 century in long-term analysis literature. Foresight issue for many states such as European Unions is considered as one of important and applicable issues in policy making field and tries to have the first role in foresight (Steenbergen, 2005). Sardar (2010) believes that all activities for foresight from prediction to landscaping, from layer analysis to millennium project have direct effect on present time such as they can change people perceptions, make us aware of coming dangers and chances, give us motivations to do certain activities or oblige us to invent or discover, and encourage us to change and mediate, and also they can excite society for social reactions, paralyze by fear, empower or run outside, tell us our believed cultures and systems are important or not.

Since the most important part of cultural policy making is identifying society members' cultural needs to formulate the most proper arriving way (Langsted, 1990), foresight can be a proper instrument for policy making in culture field which is today an intelligent policy instrument and inseparable element of policy making processes. Strategic intelligence in a short definition is: "search, processes, spread, and protection information regarded to decision making so that guaranteeing transferring information to proper person in proper time to select proper decision. Quality and effectiveness of intelligence policy have a forward looking. It shows to decision maker to decide in which space, how to face with future, and what will be probable consequences of future (Tubek et al., 2001) as the fourth generation of foresight includes all social and cultural activists (Jin, 2011), it can be a reason for interactive foresight communications with cultural policy making.

According to Morgan (2008), future study of culture makes social prediction capacities possible to get to a permanent solution. In addition, Yaprak (2008) proposed that foresight for culture gives deeper perception of culture as a determining factor for macro strategies and policies.

Today, there are various methods for foresight. Miles $(2005,2008)$ and Keenan $(2007)$ placed foresight methods in 4 groups. First group includes methods with identifying issues (such as environmental scanning, strength, weakness, opportunities, threats (SWOT) analysis, issue survey), second group includes methods with extrapolative approaches (such as trend extrapolation, simulation modelling, genius force casting, Delphi), third group includes creative approaches (brainstorming, experts panels, cross impact analysis, scenarios), in addition, fourth group is methods with prioritization approach (such as critical and (key) technologies, and technology road mapping)

The usefulness of foresight are discovering, creation, and trying favorite views and ideals for future. Having an ideal for future in decision making, strategies, and planning can be useful and finally can increase favorite future occurrence. If these ideals aren't examined by foresight methods, harms occur which originate from guiding people to impossible purposes and plans. By prediction methods we can determine factors making disturbance in plans and goals' achievement. In addition, by foresight methods we can make common views in a state or an organization and get to public agreement. The importance of such collaboration or agreement in level of all organizations in state and alignment all effective institutions to get to a common purpose is vivid for all people. Clearly, selecting even a wrong method increases guarantees of getting to results for its formulated system and structure. The most important reason of using foresight methods is to declare what are needed for an accurate decision making but this information in not accessible now. We can declare hypotheses to be examined and changed if necessary by this information (Choochun, 2001)

There are indexes and criterions to select foresight methods in foresight processes. According to Popper idea (2008), foresight methods have been influenced by dominance of intuition, vision, acceleration and sometimes inexperience of executors' and organizers irresponsibility while selecting foresight methods is possible by considering some factors. Popper (2008) classified foresight methods in pattern of diamond based on 2 qualitative and quantitative methods and also 4 criterions of interaction (participatory instruments), evidences (explanatory instruments), creativity (exploratory instruments), and experts ability (advisory instruments). In this classification, methods are extrapolated and modeled by quantitative methods and tend toward criterion, while methods such as map rodding, Delphi with semiquantitative nature tend toward expertise and methods of brainstorming, future study workshops, and conferences with qualitative nature tend toward interaction index. Finally, methods of semi-scenario, scenarios, and science fiction tends to creativity. This method classifies foresight methods based on nature so that 4 indexes of interaction, expert ability, evidence and creativity are basis of method selection. Figure (1) shows Popper diamond. 


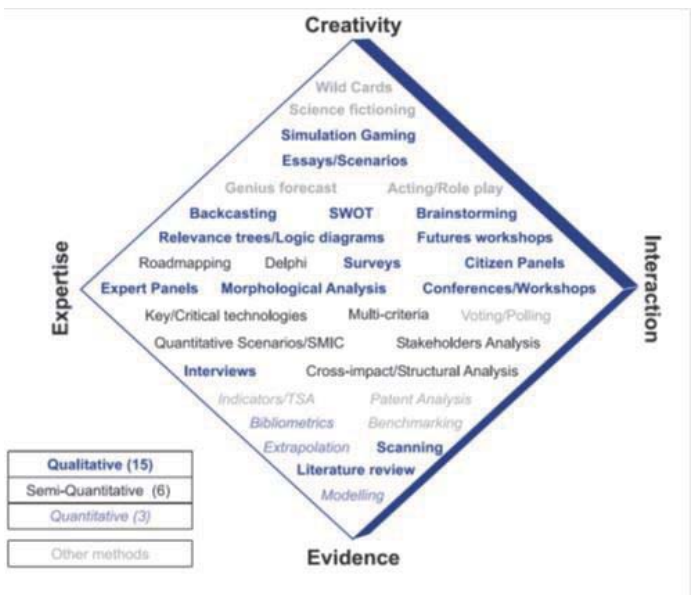

Figure 1. Popper diamond (2008)

In the rest, Popper classified 9 indexes influencing foresight methods based on application frequency in foresight projects including:

1. Geographical behavior and environment

2. Region coverage

3. Governance level and territories

4. Time horizon

5. Financial support

6. Purpose groups

7. Participation amount and level

8. Outputs

9. Method combination power

In addition, in UNIDO project (Miles, 2005), foresight methods can be proposed based on similar indexes to Popper (2008) under the title of common features in time horizon pattern, foresight process value, variety and combination of methods in selecting foresight methods. Based on each foresight methods, according to their features and nature, they are used for a certain purpose.

Abbasi et al (2008) mentioned determination of time horizon, determination financial resources (financial, informational, equipment, and installations), covering issues determination, key beneficiaries determination, participation, regional coverage. Keenan (2007) in a research titled "review on used methods in foresight" introduced indexes of resources (money or time), favorite participation amount and extension of experts and beneficiaries in foresight projects, foresight various methods needs to qualitative and quantitative data, properness of methods combination, processorientation, result-orientation from foresight project output, support of methods from each other and expectations as indexes of foresight method selection.

Information process and collecting power based on evidence, ability to produce coded on-time output (related to process), using creativity, capacity of combination with other methods, reliance on expert power, specialty, implicit knowledge and people experience, past information and statistics in foresight field, capacity of participation (Popper, 2008), reinforcing human resources and forces to use method (CIRIA, 2000; Karlsen and Karlsen, 2013), method ability in making landscape (Gavigan and Scapolo, 1999), reliance and credit of output (Miles 2005; Keenan 2007), ability of method in discoursing (Da Costa et al., 2008), method ability in identification priorities (Martin and Irvine, 1989) are indexes which are considered in selecting foresight methods. Poteralska and Sacio (2013) in a research under the title of "evaluating foresight projects of technology proposed that for daily increasing of foresight methods proposed that need to foresight evaluation is undeniable for daily increasing trend of foresight methods. Therefore, evaluation is mentioned as a centralized part of foresight projects necessarily. To evaluate foresight project, precision in national and metatransnational territories and indexes have a lot of importance. In addition, systematic and organized relationship of valuation on foresight quality should be mentioned. 
Nonetheless, exploring what methods should be used for foresight approaches in cultural field is still questionable. Are selecting foresight methods in industry and science fields usable in cultural field? Can necessities and constrains of cultural issues that make cultural policies soft and intangible influence foresight methods. Anyway, attention to foresight methods and consequently indexes to select methods need exploration. Issue of the present research tries to show which indexes have better efficiency and application in cultural policy making.

\section{Objectives of Research}

This study aims to identify indicators of evaluation and selection of Foresight methods in cultural policy-making process. Also this research aims to identify indicators of research literature According to the experts categorize and Scoring.

\section{Method and Materials}

The present research is applicable according to purpose and surveying according to nature. Data collection instrument is researcher's composed questionnaire and based on obtained indexes for theoretical bases and specialized interviews with experts an issue authorities. Face and content validity of research instrument was confirmed and validity of its structure was confirmed by analysis of structure. Instrument reliability was estimated 0.88 by alpha Cronbach coefficient. Research population was 70 experts that 60 ones were selected as Cochran's sample volume formula. To analyze data, average and t-test of one-variable and also factor analysis test using KMO coefficient to satisfy number of samples, and Friedman ranking test was used. Using factor analysis declares whether questionnaire measures indexes or not. In factor analysis, questions proposed to evaluate an index or a certain feature should have common factor loadings. One-variable t-test was used to explore average of people ideas than extracted indexes.

2 bases of research literature and also interview with experts have been used in this research to identify indexes. Indexes such as penetration coefficient in cultural field, awareness in method, ability to make mental challenge, ability to break paradigm, responsiveness to new evolutions, ability to perceive qualitative conceptions, risk taking, risk management in using method, ability to identify future making trends and events, inventing new alternatives, amount of saving gathered information, method ability in making systematic look (holism), method ability in determining existed conditions (objective realities), method ability in adaptation with macro purposes, alignment with society values and beliefs, method ability in imaging probable and possible future, and method flexibility were extracted by deep and semistructured interview.

\section{Results}

Table (1) shows indexes of selecting foresight methods in cultural policy making.

Table 1. factor loading, KMO measure, and evaluation indexes average, and selecting foresight methods in cultural policy making

\begin{tabular}{|c|c|c|c|c|c|c|c|c|c|c|}
\hline & Indexes to select foresight methods & $\begin{array}{l}\text { KMO } \\
\text { size }\end{array}$ & $\begin{array}{l}\text { Factor } \\
\operatorname{load} 1\end{array}$ & $\begin{array}{l}\text { Factor } \\
\text { load } 2\end{array}$ & $\begin{array}{l}\text { Factor } \\
\text { load } 3\end{array}$ & $\begin{array}{l}\text { Factor } \\
\text { load } 4\end{array}$ & $\begin{array}{l}\text { Factor } \\
\text { load } 5\end{array}$ & $\begin{array}{l}\text { Factor } \\
\text { load } 6\end{array}$ & $\begin{array}{l}\text { Factor } \\
\operatorname{load} 7\end{array}$ & Average \\
\hline 1 & $\begin{array}{l}\text { Method ability in adaptation with macro purposes in } \\
\text { cultural field of policy making }\end{array}$ & \multirow{5}{*}{0.579} & -0.083 & & & & & & & 4.12 \\
\hline 2 & Alignment with society values and beliefs & & 0.367 & & & & & & & 4.02 \\
\hline 3 & $\begin{array}{l}\text { Method ability in possible and probable imaging of } \\
\text { future in culture field }\end{array}$ & & 0.474 & & & & & & & 5.47 \\
\hline 4 & Method ability in making favorite cultural landscape & & 0.357 & & & & & & & 4.22 \\
\hline 5 & Method ability in making systematic attitude (holism) & & 0.917 & & & & & & & 5.70 \\
\hline 6 & $\begin{array}{l}\text { method in accurate determination of present } \\
\text { conditions (objective realities) }\end{array}$ & \multirow{5}{*}{0.812} & & 0.537 & & & & & & 4.50 \\
\hline 7 & $\begin{array}{l}\text { Ability of information gathering and processing } \\
\text { based on witnesses }\end{array}$ & & & -0.042 & & & & & & 4.97 \\
\hline 8 & Protecting gathered information security & & & 0.322 & & & & & & 47.5 \\
\hline 9 & Reliability and credit of outputs & & & 0.751 & & & & & & 3.58 \\
\hline & $\begin{array}{l}\text { Ability to produce coded on-time outputs (related to } \\
\text { process) }\end{array}$ & & & 0.769 & & & & & & 3.98 \\
\hline
\end{tabular}




\begin{tabular}{|c|c|c|c|c|c|c|c|c|}
\hline 11 Using creativity & & 0.751 & & & & & & 4.10 \\
\hline \begin{tabular}{|l|l|}
12 & Ability to make intuitive convergence \\
\end{tabular} & & 0.801 & & & & & & 3.38 \\
\hline \begin{tabular}{|l|l|}
13 & Making new alternatives \\
\end{tabular} & & 0.883 & & & & & & 3.44 \\
\hline \begin{tabular}{|l|l|}
14 & Method ability in cultural discoursing \\
\end{tabular} & & 0.907 & & & & & & 3.69 \\
\hline 15 Ability of identification futuristic trends and events & & -0.029 & & & & & & 4.12 \\
\hline 16 Ability of identification strategic priorities & & 0.935 & & & & & & 90.3 \\
\hline \begin{tabular}{|l|l|}
17 & Risk taking and management in using method \\
\end{tabular} & & -0.079 & & & & & & 5.08 \\
\hline \begin{tabular}{|l|l|}
18 & Capacity of combination with other methods \\
\end{tabular} & & 0.746 & & & & & & 3.64 \\
\hline $19 \begin{array}{l}\text { Ability of general conceptions perception in culture } \\
\text { field }\end{array}$ & & 0.403 & & & & & & 4.90 \\
\hline \begin{tabular}{|l|l|}
20 & Method capacity for cultural participation \\
\end{tabular} & \multirow{3}{*}{0.632} & & 0.868 & & & & & 5.02 \\
\hline 21 Method ability in social networking & & & 0.664 & & & & & 5.75 \\
\hline \begin{tabular}{|l|l|}
22 & Relationship with data state \\
\end{tabular} & & & -0.505 & & & & & 51.3 \\
\hline \begin{tabular}{|l|l|}
23 & Method flexibility \\
\end{tabular} & \multirow{9}{*}{0.669} & & & 0.197 & & & & 12.6 \\
\hline \begin{tabular}{|l|l}
24 & $\begin{array}{l}\text { Reliance on implicit knowledge of experts and } \\
\text { people experience }\end{array}$ \\
\end{tabular} & & & & 0.451 & & & & 45.5 \\
\hline \begin{tabular}{|l|l|}
25 & responsiveness to new evolutions \\
\end{tabular} & & & & 0.886 & & & & 12.5 \\
\hline \begin{tabular}{|l|l|}
26 & Reliance on evidences \\
\end{tabular} & & & & 0.678 & & & & 51.3 \\
\hline $27 \begin{array}{l}\text { Past information and statistics in mentioned field of } \\
\text { foresight }\end{array}$ & & & & 0.641 & & & & 5.24 \\
\hline \begin{tabular}{|l|l|}
28 & Ability to break paradigm \\
\end{tabular} & & & & 0.192 & & & & 4.69 \\
\hline \begin{tabular}{|l|l|}
29 & Method analytical ability \\
\end{tabular} & & & & 0.536 & & & & 4.58 \\
\hline \begin{tabular}{|l|l|}
30 & Intuitive ability and method explanatory \\
\end{tabular} & & & & 0.886 & & & & 4.86 \\
\hline 31 Ability to make mental challenge & & & & 0.446 & & & & 4.87 \\
\hline \begin{tabular}{|l|l|}
32 & Capacity to make experts â $€$ TM participation \\
\end{tabular} & \multirow{3}{*}{0.498} & & & & 0.999 & & & 5.50 \\
\hline \begin{tabular}{|l|l|}
33 & Ability to make players participation \\
\end{tabular} & & & & & 0.277 & & & 4.83 \\
\hline \begin{tabular}{|l|l|}
34 & Ability to use facilitator participation \\
\end{tabular} & & & & & -0.106 & & & 4.31 \\
\hline 35 Application extension in related fields to culture & \multirow{3}{*}{0.530} & & & & & 0.976 & & 4.15 \\
\hline \begin{tabular}{|l|l|}
36 & Penetration coefficient in culture field \\
\end{tabular} & & & & & & 0.734 & & 4.27 \\
\hline \begin{tabular}{|l|l|}
37 & Awareness about method \\
\end{tabular} & & & & & & -0.236 & & 4.37 \\
\hline 38 Accessibility of financial resources to use method & \multirow{5}{*}{0.658} & & & & & & 0.653 & 3.40 \\
\hline $39 \begin{array}{l}\text { Accessibility of informational resources to use } \\
\text { method }\end{array}$ & & & & & & & 0.969 & 3.97 \\
\hline \begin{tabular}{|l|l|}
40 & Process sophistication in method \\
\end{tabular} & & & & & & & 0.885 & 3.95 \\
\hline 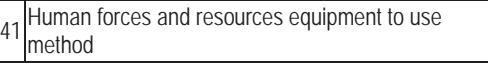 & & & & & & & 0.656 & 3.28 \\
\hline \begin{tabular}{|l|l|}
42 & Time-consuming index of using method \\
\end{tabular} & & & & & & & 0.444 & 3.47 \\
\hline
\end{tabular}

According to findings of this table, the most factor coefficient in indexes of evaluation and selection of foresight methods in first group is related to item 5 with factor load of 0.917 and the least factor coefficient is related to item 2 with factor load 0.367 and KMO for sampling sufficiency was 0.579 that is high and acceptable value. In addition, factor load of each evaluation and foresight methods selection indexes were stayed in the first group higher than 0.3 and item 1 was deleted for not having proper factor load. The biggest factor coefficient in evaluation and foresight methods selection in the second group was related to item 16 with factor load of 0.935 and the least factor coefficient was related to item 19 that was 0.403 . KMO value for sampling sufficiency was 0.812 that was high and acceptable. In addition, factor load of evaluating and foresight selection indexes were in the second group higher than 0.3 and items 7, 15, 17 were deleted for not having factor loads.

According to findings of table, the most factor coefficient in indexes of selection and evaluation of the third group was related to item 20 with factor load of 0.868 and the least factor load was related to item 21 with factor load 0.664 . $\mathrm{KMO}$ for sampling efficiency was 0.632 that was high and acceptable. In addition, factor load of each indexes of foresight methods selection in the third group higher than 0.3 were stayed and item 22 was deleted for not having factor load. The most factor load in indexes of foresight methods selection of the fourth group was related to items 25 and 30 with factor load 0.886 and the least factor load related to item 31 was with factor load 0.446 . KMO value of sampling efficiency was 0.669 that is high and acceptable. In addition, factor load of each indexes for foresight methods selection in the fourth group were stayed which were higher than 0.3 and items 23 and 28 were deleted for not having proper factor load. 
The most factor coefficient in selection and evaluation indexes of foresight methods of the fifth group was related to item 32 with factor load of 0.999 . KMO for sampling efficiency was 0.498 that was high and acceptable. In addition, factor load of each indexes of foresight methods selection in the fifth group higher than 0.3 were stayed and item 23 and 34 were deleted for not having factor load. The most factor load in indexes of foresight methods selection of the sixth group bigger than 0.3 was stayed and item 37 was deleted for not having factor load. The most factor coefficient in foresight methods selection and evaluation indexes of the seventh group was related to item 39 with factor load of 0.969 and the least factor load was related to item 42 with factor load 0.444 . KMO for sampling efficiency was 0.658 that was high and acceptable. In addition, factor load of each sub elements on indexes of foresight methods indexes $f$ seventh group were all higher than 0.4 .

Table 2. average, standard deviation, one-variable t-test, and Friedman formulation for evaluation and foresight methods selection indexes in cultural policy making.

\begin{tabular}{|c|c|c|c|c|c|c|c|c|c|c|}
\hline Row & Indexes to select foresight methods & Mean & $\begin{array}{c}\text { Std. } \\
\text { Deviation }\end{array}$ & $\begin{array}{l}\text { Std. Error } \\
\text { Mean }\end{array}$ & $\mathrm{T}$ & Df & Sig & $\begin{array}{l}\text { Mean } \\
\text { Rank }\end{array}$ & $\begin{array}{l}\text { Chi- } \\
\text { Square }\end{array}$ & Sig \\
\hline 1 & Alignment with society values and beliefs & 4.02 & 1.662 & 0.215 & 4.738 & 59 & .000 & 18.92 & \multirow{32}{*}{285.41} & \\
\hline 2 & $\begin{array}{l}\text { Method ability in possible and probable imaging of future in } \\
\text { culture field }\end{array}$ & 5.47 & 1.432 & 0.185 & 13.346 & 59 & .000 & 27.36 & & \\
\hline 3 & Method ability in making favorite cultural landscape & 4.22 & 1.576 & 0.205 & 5.946 & 58 & .000 & 19:49 & & \\
\hline 4 & Method ability in making systematic attitude (holism) & 5.70 & 1.331 & 0.172 & 15.707 & 59 & .000 & 31.71 & & \\
\hline 5 & $\begin{array}{l}\text { method in accurate determination of present conditions } \\
\text { (objective realities) }\end{array}$ & 4.05 & 1.580 & 0.213 & 4.949 & 54 & .000 & $19: 22$ & & \\
\hline 6 & Protecting gathered information security & 5.47 & 1.818 & 0.235 & 10.512 & 59 & .000 & 29.09 & & \\
\hline 7 & Reliability and credit of outputs & 3.58 & 1.647 & 0.218 & 2.654 & 56 & .010 & 16.60 & & \\
\hline 8 & Ability to produce coded on-time outputs (related to process) & 3.98 & 1.656 & 0.216 & 4.561 & 58 & .000 & $21: 00$ & & \\
\hline 9 & Using creativity & 4.10 & 1.605 & 0.209 & 5.273 & 58 & .000 & 19.65 & & \\
\hline 10 & Ability to make intuitive convergence & 3.38 & 1.814 & 0.238 & 1.592 & 57 & 117 & $16: 14$ & & \\
\hline 11 & Making new alternatives & 3.44 & 1.465 & 0.191 & 2.310 & 58 & 0.024 & 15.86 & & \\
\hline 12 & Method ability in cultural discoursing & 3.69 & 1,600 & 0.208 & 3.336 & 58 & .001 & 17.67 & & \\
\hline 13 & Ability of identification strategic priorities & 3.90 & 1.626 & 0.212 & 4.243 & 58 & .000 & 19.69 & & \\
\hline 14 & Capacity of combination with other methods & 3.64 & 1.651 & 0.217 & 2.942 & 57 & .005 & 18.68 & & \\
\hline 15 & Ability of general conceptions perception in culture field & 4.09 & 1.678 & 220 & 4.929 & 57 & .000 & $18: 41$ & & \\
\hline 16 & Method capacity for cultural participation & 5.02 & 1.456 & 0.190 & 10.639 & 58 & .000 & 24.26 & & 0.000 \\
\hline 17 & Method ability in social networking & 5.75 & 1.230 & 0.159 & 17.319 & 59 & .000 & 29.88 & & \\
\hline 18 & $\begin{array}{l}\text { Reliance on implicit knowledge of experts and people } \\
\text { experience }\end{array}$ & 5.45 & 1.558 & 0.205 & 11.968 & 57 & .000 & 28.31 & & \\
\hline 19 & responsiveness to new evolutions & 5.12 & 1.651 & 0.215 & 9.855 & 58 & .000 & 25.62 & & \\
\hline 20 & Reliance on evidences and documents & 3.51 & 1.612 & 0.210 & 2.423 & 58 & 0.019 & 16.81 & & \\
\hline 21 & Past information and statistics in mentioned field of foresight & 5.24 & 1.699 & 0.223 & 10.044 & 57 & .000 & 26.77 & & \\
\hline 22 & Method analytical ability & 4.58 & 1.914 & 0.249 & 6.327 & 58 & .000 & $20: 54$ & & \\
\hline 23 & Intuitive ability and method explanatory & 4.86 & 1.457 & 0.193 & 9.636 & 56 & .000 & 23.64 & & \\
\hline 24 & Ability to make mental challenge & 4.87 & 1.490 & 0.192 & 9.706 & 59 & .000 & $23: 38$ & & \\
\hline 25 & Capacity to make experts' participation & 5.50 & 1.260 & 0.165 & 15.110 & 57 & .000 & 29.08 & & \\
\hline 26 & Application extension in related fields to culture & 4.15 & 1.730 & 0.225 & 5.117 & 58 & .000 & 19:14 & & \\
\hline 27 & Penetration coefficient in culture field & 4.27 & 1.726 & 0.223 & 5.685 & 59 & .000 & $21: 04$ & & \\
\hline 28 & Accessibility of financial resources to use method & 3.40 & 1.787 & 0.231 & 1.734 & 59 & 0.088 & 13.94 & & \\
\hline 29 & Accessibility of informational resources to use method & 3.97 & 1.857 & 0.242 & 3.997 & 58 & .000 & 17.83 & & \\
\hline 30 & Process sophistication in method & 3.95 & 1.795 & 0.234 & 4.062 & 58 & .000 & $18: 37$ & & \\
\hline 31 & Human forces and resources equipment to use method & 3.28 & 1.497 & 0.193 & 1.466 & 59 & 0.148 & $14: 06$ & & \\
\hline 32 & Index of method usage being time-consuming & 3.47 & 1.478 & 0.192 & 2.466 & 58 & 0.017 & 15.86 & & \\
\hline
\end{tabular}

As it is seen from table (2); although, all identified indexes have averages higher than 3, except indexes of "human resources and forces amount to use method", "accessibility of financial resources to use method", "power to make intuitive convergence", other existed indexes are significant in policy making process of other indexes in level of $(P<0.05)$ 
according to experts' ideas.

Result obtained from ranking indexes show that since "method ability to make systematic attitude (holism)", "ability to make expert participation", "method ability in social networking", "security of gathered information", "reliance on implicit expert, knowledge, specialty, and experience of people" and "method ability in imagining of possible and probable future in culture field" all have higher rank than other indexes in foresight methods selection in cultural policy making, significance level $\mathrm{P}<0.001$ and $\mathrm{Chi}-2$ coefficient of 285.41 are significant in ranking.

\section{Discussion and Conclusion}

Foresight is an integrated framework to make extensive future landscape and provides list of priorities. Hence, prioritization is proposed as a purpose accomplished by foresight.

On the other hand, the main responsibility of policy makers are prioritization, selection instrument for policy execution and evaluating progress based on integrated framework. Having a framework for policy making gives logic and philosophy to guide policies and plans. A proper framework for policy making can be useful for mutual perception making and transferring, guiding activities and adaptation activities together. In this integrated policy making framework, having an extensive framework for future and list of priorities is inevitable.

Although, several indexes are mentioned in foresight methods selection, policy making in cultural field needs refinery in indexes of foresight methods selection for being new. The present research was performed by purpose of answering to this question which indexes are valid in evaluation and selection of foresight policy making. Results of this research showed that 32 among 42 identified indexes have acceptable factor load. Amongst, indexes such as "method ability in making systematic attitude (holism)", "capacity to make experts' participation", "method ability in social networking", "saving gathered information security", "reliance on implicit expert, specialty, and experiences of people" and "method ability in imaging possible and probable future in culture field" have higher rank than other indexes in selecting foresight methods in cultural policy making.

In analysis results, we can infer that for different nature of culture in policy making field and escape from Populist attitude in cultural policy making, the necessity of making capacities for experts' participation in foresight method are significantly important. In this regards, methods having ability to participate experts in cultural policy making process, have high credit. On the other hand, as culture is a social matter, its policy making needs social networks in information fluidizing and communications so 2 methods of foresight with ability of networking has high ability. In addition, necessity of protecting information in policy making field for importance of culture as one aspect of soft invasion beside economics and politics needs foresight methods to protect information of culture as much as possible. What this research shows is that selection of foresight methods can't be proposed by indexes such as financial, territorial, and time indexes and it is necessary to mention to different and proper cultural and cultural policy indexes that this research focused on them.

The results of this research in aspects of method combination, capacity of participate experts are in agreement with studies of Popper (2008), Horton (1999), Gavigan and Scapolo (1999), Martin (1995) and in networking, process sophistication, favorite landscape are in agreement with Keenan (2007), Miles (2005), Da Costa et al. (2008), Martine and Irvine (1989), Miles and Miles (2003)

An interesting point in this research is culture role in evolution of evaluation and selection indexes of foresight methods in policy making. For importance of culture issue such as ability in making favorite cultural landscape for future, method ability in imaging possible and probable future in culture field, saving security of gathered data method ability in cultural participation, responsiveness to new evolutions, capacity to participate experts, penetration coefficient in culture field have more credit than pubic indexes of selecting foresight methods. In this regard, the conclusion of the present research is reliance on existed indexes which are mainly used in industry, education, services, etc. and has high origin in culture field. Attention to indexes with abilities of nature perception and cultural features are significantly important.

\section{References}

Abbasi Shahkuh, K., Soltani Delgosha M., Vahedian A., Abdollahi A. (2008). Providing a process framework for foresight based on metacombination method. Iran management science chapter, 3(45), 11-72

Ashtarian, K, (2012). An introduction to cultural policy making method. Tehran: socialist express.

Choo, C. W. (2001). Environmental scanning as information seeking and organizational learning. Information Research, 7(1), 1-7.

Da Costa, O, P Warnke, F Scapolo and C Cagnin (2008). The impact of foresight on policy making: insights from the FORLEARN mutual learning process. Technology Analysis and Strategic Management, 20(3), 369-387.

Gavigan, P. J. \& Scapolo, F. (2001). Foresight and the long-term view for regional development. The IPTS Report, 56: 19-29

Gavigan, J. P., \& Scapolo, F. (1999). A comparison of national foresight exercises. Foresight, 1(6), 495-517. 
Hergert, R. (2013). Organizational Perception and Cultural Orientation: A Context-Based Approach to Corporate Foresight. In Narrative and Innovation (pp. 31-46). Springer Fachmedien Wiesbaden.

Horton, A.(1999). Forefront: A simple guide to successful foresight .Foresight, 1(1), 5-9.

Jin, Z. (2011). Global technological change: from hard technology to soft technology. Intellect Books.

Karlsen, J. E., \& Karlsen, H. (2013). Classification of tools and approaches applicable in foresight studies. In Recent Developments in Foresight Methodologies (pp. 27-52). New York: Springer US.

Keenan, M. (2007). Overview of methods used in foresight. UNIDO Technology Foresight Training Programme for CEE/NIS. Bratislava: Slovakia.

Khazaee, S. (2008). Step by step guide for strategic future study. Tehran: Kashf Ayandeh express

Langsted, J. (1990). Strategies: Studies in Modern Cultural Policy. Aarhus University Press.

Malaska, P. WFSF-L@list1.ucc.nau.edu, postdated 22 May 2008.

Martin, B. R., and Irvine, J. (1989). Research Foresight: Priority-setting in Science. London: Pinter Publishers.

Miles, I. (2005). Scenario planning. UNIDO Technology Foresight Manual, Volume I-Organization and Methods, UNIDO, Vienna, pp. 168-93.

Miles, I. (2008). From futures to Foresight. In Georghiou, L., Cassingena, J., Keenan, M., Milles, I. and Popper, R. (Eds), the Handbook of Technology Foresight, Edward Elgar, Aldershot.

Morgan, D. (2008). American culture, corporate culture, and the transformation of business practice: the role of social foresight in a restorative economy. Foresight, 10(4), 31-42.

Popper, R. (2008). How are foresight methods selected?. Foresight, 10(6), 62-89.

Poteralska, B., \& Sacio-Szymańska, A. (2014). Evaluation of technology foresight projects. European Journal of Futures Research, 2(1), 1-9.

Salehi Amiri, S. R. and Kavusi, E. (2009). An introduction on comprehensive cultural plan execution steps, cultural planning. Research 28.trategic research center of Expediency council

Sardar Z. (2010). The Namesake: Futures; futures studies; futurology; futuristic;

Steenbergen V. (2005). Bart: Scenarios as a Powerful Tool for Public Policy. As presented at the Prague Workshop on Futures Studies Methodology, http://ceses.cuni.cz/english/051019.php. To be published in the proceedings.

Tübke A., Ducatel K., Gavigan J., Moncada-Paterno-Castello P. (2001). Strategic Policy Intelligence: Current Trends, the State of Play and Perspectives. IPTS Technical report Series EUR 20137 EN.

University of Durham Business School. (2000). Leading into the Future: Foresight Perspectives from the Construction Industry Research and Information Association (CIRIA), November.

Yaprak, A. (2008). Culture study in international marketing: a critical review and suggestions for future research. International Marketing Review, 25(2), 215-229. 